\title{
Effects of Leaderboards in Games on Consumer Engagement ${ }^{*}$
}

\author{
Extended Abstract
}

\author{
Laura C. Amo \\ State University of New \\ York at Buffalo \\ lccasey@buffalo.edu
}

\author{
Ruochen Liao \\ State University of New \\ York at Buffalo \\ rliao2@buffalo.edu
}

\author{
H. Raghav Rao \\ University of Texas at San \\ Antonio \\ hr.rao@utsa.edu
}

\author{
Gretchen Walker \\ The Tech Museum of \\ Innovation \\ gwalker@thetech.org
}

\section{ACM Reference format:}

L. C. Amo, R. Liao, H. R. Rao, and G. Walker. 2018. Effects of Leaderboards in Games on Consumer Engagement. In SIGMIS-CPR '18, Fune 18-20, 2018, Buffalo-Niagara Falls, NY, USA, 2 pages. https://doi.org/10.1145/3209626.3209708

\section{INTRODUCTION}

Gamification is the process of adding games or game-like elements to a non-game task in order to encourage participation and engagement [8]. Gamification, as a means of engaging consumers $[6,10,16]$, has become more and more popular and implemented in a range of user-oriented applications. However studies have shown that it may not always have the type of impact as initially projected [12, 13]. Gamification yields different, sometimes contradictory, results with regard to the engagement outcomes. Researchers have argued that gamification is not always properly implemented and may not have consistent positive effects [14], as the reward mechanisms and intensified competition could create a controlling gaming environment that could dampen the intrinsic motivation of the participants [13]. Therefore, it is important for businesses and organizations to be able to gauge the impact of gamified interventions and evaluate return on investment.

In this study, we first review prior research on consumer engagement, and posit that the different findings related to engagement outcomes may be due to the multi-facet nature of consumer behavior. Specifically, we divide engagement outcomes on four indicators and examine the effect of gamification on each of them: time-on-task, the number of attempts, the number of re-attempts, and the number of unique attempts. We compare differences between a control group and a treatment group in an informal learning environment across a 10-month period wherein a leaderboard was introduced in the treatment kiosk in the fifth month, allowing us to evaluate the change in outcomes while controlling for existing differences.

\footnotetext{
*The National Science Foundation (NSF), DGE-1523174, supported data collection associated with this study; all disclaimers apply.

Permission to make digital or hard copies of all or part of this work for personal or classroom use is granted without fee provided that copies are not made or distributed for profit or commercial advantage and that copies bear this notice and the full citation on the first page. Copyrights for components of this work owned by others than the author(s) must be honored. Abstracting with credit is permitted. To copy otherwise, or republish, to post on servers or to redistribute to lists, requires prior specific permission and/or a fee. Request permissions from Permissions@acm.org.

SIGMIS-CPR '18, June 18-20, 2018, Buffalo - Niagara Falls, USA.

(C) 2018 Copyright is held by the owner/author(s). Publication rights licensed to ACM.

ACM ISBN 978-1-4503-5037-2/17/06 ..\$15.00

http://dx.doi.org/10.1145/3084381.3084385
}

\section{LITERATURE REVIEW}

Consumer engagement originated from the relationship marketing literature in the 1990s $[1,2,16]$. However, consumer engagement lacks a clear definition, and related psychological and behavioral outcomes tend to be context-specific [11]. For example, there is evidence that certain game elements may actually be negatively related to motivation $[12,15]$ or at least not associated with long-term behavioral change [4]. Prior literature that attempts the explain the contradictory findings in the effect of gamification generally agree that while gaming elements appeal to the intrinsic motivation of individuals by making the game more interesting and engaging, material rewards and the competition for reputation and ranking would actually hurt intrinsic motivation by making the individuals feeling coerced and controlled [15].

We propose that while external factors such as ranking and reputation could potentially exert social- and peer-pressure on the participants, the participants may adopt different coping strategies in the presence of such pressure [3,5]. We integrate literatures on pride [21] and social comparison [5], and posit that while certain individuals may perceive the game environment to be controlling and harming their autonomy, other individuals may be driven to achieve higher symbolic places under the pressure.

\section{RESEARCH MODEL AND HYPOTHESES}

In certain studies, leaderboards are positively associated with time-based outcomes. Pride is a powerful motivator of time spent on a task [8] particularly when such pride is authentic and tied to a specific experience [19]. Leaderboards publicly display achievement and establish ranking, and may represent the opportunity for a consumer to take public ownership of an achievement. As such, we posit that there will be a significant increase in the average time spent at the kiosk among consumers as they would try harder to come out top of the competition. Following the same line of logic, leaderboards will likely encourage consumers to make more attempt when they run into obstacles. Literature has shown that even if a task is difficult, the prospect of experiencing pride at the end by achieving success is a powerful motivator $[9,21]$. Therefore, we hypothesize that there will be a significantly greater number of attempts by consumers once the leaderboard is added.

On the other hand, the leaderboard is just as likely to be negatively associated with re-attempts and unique attempts. Specifically, unlike points and levels, leaderboard does not provide task-related feedbacks and error cues. Participants could 
experience greater frustration when they perform below expectation but not knowing how to improve. Similarly, from a social comparison perspective [5], consumers may feel that attempting the game is not worth the effort as there are far better performers (i.e. top leaderboard scorers). As a result, we posit that the leaderboard will be negatively associated with reattempts.

Lastly, we posit that the presence of a leaderboard will be associated with fewer unique attempts; in other words, fewer consumers will even attempt the game once the leaderboard is introduced. It may be that consumers feel that attaining a score comparable to that of high scorers is not very possible or economical. Social comparison in the form of a leaderboard may lead to a destructive form of competition and negatively affect motivation [7, 13]. If consumers are not competitive or are intimidated by competitive activities, the leaderboard may actually deter them.

\section{DATA SOURCES AND METHODOLOGY}

We conducted the study at the Tech Museum of Innovation in San Jose, California. School-age students visit this museum and informal learning occurs by interacting with the mini-games at kiosks to achieve goals. Our data included multiple observations for visitors over the course of about ten months: November 1 , 2015 through August 28, 2016. A leaderboard is introduced to one of the game kiosks, Net-builder, in the middle of the study period, this intervention allows us to evaluate if changes made to one kiosk were associated with changes in engagement outcomes.

\section{RESULTS}

On average, consumer spend much longer time on Net-builder compared to other kiosks before the intervention. After the leaderboard was introduced to the Net-Builder kiosk, consumers spend an extra 60 seconds or about 35\% more time per interaction at the Net-Builder kiosk. Contrary to our hypothesis, the addition of the leaderboard to the Net-Builder kiosk did not significantly affect the average number of overall attempts. This indicates that consumers are trying harder at each attempt, but not increasing the number of attempts. Average number of attempts made by consumers on Net-builder kiosk and other game kiosks were not significantly affected by the addition of the leaderboard. But the number of re-attempt decreased at the Net-builder kiosk compared to other kiosks, as we hypothesized, and unique attempts at the Net-builder kiosk also decreased after the leaderboard is in place.

\section{DISCUSSION}

Consistent with existing findings on leaderboard effectiveness, our results suggest that leaderboards have both positive and negative effects on consumer engagement. Our findings confirm that leaderboards are not necessarily an overall effective mechanism for increasing engagement. While leaderboards may motivate certain consumers to pursue opportunities to demonstrate pride over achievement $[20,22]$, these game elements may also introduce an element of competition, eliciting fear and aversion in other consumers [12]. The overall goals and culture of the organization need to be taken into account when leaderboards are implemented as a game element.

\section{REFERENCES}

[1] Christopher, M., Payne, A., and Ballantyne, D. 1991. Relationship marketing: bringing quality customer service and marketing together. ButterworthHeinemann: Oxford, England.

[2] Crumlish, C., and Malone, E. (2009). Designing social interfaces: Principles, patterns, and practices for improving the user experience. O'Reilly Media, Inc.,: Sebastopol, CA.

[3] Deterding, S. 2011. Situated motivational affordances of game elements: A conceptual model. In Proceedings of Gamification: Using game design elements in non-gaming contexts. ACM Computer-Human Interaction [CHI], Vancouver, British Columbia.

[4] Farzan, R., DiMicco, J. M., Millen, D. R., Dugan, C., Geyer, W., and Brownholtz, E. A. 2008. Results from deploying a participation incentive mechanism within the enterprise. In Proceedings of the SIGCHI conference on Human Factors in Computing Systems.

[5] Festinger, L. (1954). A theory of social comparison processes. Human Relations, 7, 2 (1954), 117-140. DOI: https://doi.org/10.1177/001872675400700202

[6] Hamari, J., Koivisto, J., and Sarsa, H. 2014. Does gamification work?--a literature review of empirical studies on gamification. In Proceedings of the 2014 47th Hawaii International Conference on System Sciences. IEEE Computer Society, Hawaii.

[7] Hanus, M. D., and Fox, J. 2015. Assessing the effects of gamification in the classroom: A longitudinal study on intrinsic motivation, social comparison, satisfaction, effort, and academic performance. Computers \& Education, 80, 152-161.

[8] Landers, R. N., and Landers, A. K. 2014. An empirical test of the theory of gamified learning: The effect of leaderboards on time-on-task and academic performance. Simulation \& Gaming, 45(6), 769-785.

[9] Landers, R. N., Bauer, K. N., \& Callan, R. C. 2017. Gamification of task performance with leaderboards: A goal setting experiment. Computers In Human Behavior, 71, 508-515.

[10] Liu, D., Santhaham, R., and Webster, J. 2017. Toward meaningful engagement: A framework for design and research of gamified information systems. MIS Quarterly, 41(4), 1011-1034.

[11] Malone, T. W. 1981. Toward a theory of intrinsically motivating instruction. Cognitive Science, 5(4), 333-369.

[12] Mekler, E. D., Brühlmann, F., Opwis, K., and Tuch, A. N. 2013. Do points, levels and leaderboards harm intrinsic motivation?: An empirical analysis of common gamification elements. Paper presented at the Proceedings of the First International Conference on Gameful Design, Research, and Applications.

[13] Orosz, G., Farkas, D., and Roland-Lévy, C. (2013). Are competition and extrinsic motivation reliable predictors of academic cheating? Frontiers in Psychology, 4.

[14] Richter, G., Raban, D.R., and Rafaeli, S. Studying gamification: the effect of rewards and incentives on motivation. Gamification in education and business: Springer, 2015, pp. 21-46.

[15] Ryan, R., and Deci, E. 2000. Intrinsic and Extrinsic Motivations: Classic Definitions and New Directions. Contemporary educational psychology, 1(25), 54-67. doi:10.1006/ceps.1999.1020 \%\2017-01-22 15:39:00

[16] Schiff, J. L. (2017). How gamification improves customer engagement and retention. Retrieved from

https://www.cio.com/article/3184368/small-business/how-gamificationimproves-customer-engagement-and-retention.html

[17] Stieglitz, S., and Dang-Xuan, L. 2013. Emotions and information diffusion in social media-sentiment of microblogs and sharing behavior. Fournal of Management Information Systems, 29(4), 217-248.

[18] Suh, A., Wagner, C., and Liu, L. 2016. Enhancing User Engagement through Gamification. Fournal of Computer Information Systems, 1-10.

[19] Tangney, J. P. 1999. The self-conscious emotions: Shame, guilt, embarrassment and pride.

[20] Werbach, K., and Hunter, D. 2012. For the win: How game thinking can revolutionize your business: Wharton Digital Press.

[21] Williams, L. A., and DeSteno, D. 2008. Pride and perseverance: the motivational role of pride. fournal of Personality and Social Psychology, 94(6), 1007.

[22] Yee, N. 2006. Motivations for play in online games. CyberPsychology \& Behavior, 9 (6), 772-775. 